\title{
Correlation Between Fetal Anterior-Posterior Thigh Diameters and
} Routine Ultrasound Parameters in Determining Gestational Age

\author{
Nazanin Farshchian (iD ${ }^{1,}{ }^{*}$, Farhad Naleini ${ }^{1}$ and Parisa Bahrami Kamangar ${ }^{1}$ \\ ${ }^{1}$ Department of Radiology, Imam Reza Hospital, Kermanshah University of Medical Sciences, Kermanshah, Iran \\ "Corresponding author: Associate Professor, Department of Radiology, Imam Reza Hospital, Kermanshah University of Medical Sciences, Kermanshah, Iran. Tel: \\ +98-8334276310, Email: nfarshchian@kums.ac.ir
}

Received 2019 April 29; Revised 2019 July 30; Accepted 2019 July 30.

\begin{abstract}
Background: Determining the exact gestational age can prevent many complications and unpleasant consequences of pregnancy such as fetal growth retardation, premature birth and prenatal mortality.

objectives: This study aimed to measure fetal anterior-posterior thigh diameter, as a new method for determining gestational age, and to compare it with routine ultrasound parameters (biparietal diameter, femur length).

Methods: In this study, 105 pregnant women with gestational age 18 - 28 weeks who presented to Kermanshah Imam Reza Hospital were recruited. Gestational age was determined based on last menstrual period (LMP). Then, ultrasound was performed to measure gestational age with anterior-posterior thigh diameter and other routine parameters (biparietal diameter, femur length). Finally, the results were evaluated with KS and Spearman's correlation coefficient in SPSS version 22. Significance level was set as 0.05.

Results: A significant correlation existed between estimation of gestational age based on ultrasound parameters and LMP, and between anterior-posterior thigh diameter and routine ultrasound parameters $(\mathrm{P}<0.05)$. Hence, anterior-posterior thigh diameter is as good as biparietal diameter and femur length for estimation of gestational age.

Conclusions: According to the results, using anterior-posterior thigh diameter can be a reliable method in estimation of gestational age in the second trimester in addition to routine parameters.
\end{abstract}

Keywords: Gestational Age, Anterior-Posterior Thigh Diameter (APDT), Last Menstrual Period (LMP), Ultrasound

\section{Background}

Ultrasound is currently used to determine gestational age by measuring different values such as gestational sac diameter, fetal crown-rump length (CRL), fetal biparietal diameter (BPD), femoral length (FL), abdominal circumference (AC), length of other fetal long bones such as the arm, fetal transverse cerebellar diameter (TCD) and fetal foot length (1-3). The exact estimation of gestational age depends on the correct measurement of the above diameters $(2,3)$. Also, variations in fetal measurement results by different individuals will increase with gestational age, and earlier measurements determine gestational age more accurately $(2,3)$. Many studies have been conducted in this field in different countries, and various measurements and tables have been developed to determine fetal age based on measuring different diameters $(4,5)$. Textbooks emphasize that fetal growth is influenced by genetic factors, which in turn are affected by ethnic and geographic differences, and this is more significant in the third trimester $(3,6)$.

It is noteworthy that the mean gestational sac diame- ter and CRL are used to determine gestational age in the first trimester measuring, and parameters such as BPD, FL, AC, TCD, and head circumference (HC) can be used in the second and third trimesters. The measurement of these parameters, however, has some features and drawbacks (7). In the third trimester, the accuracy of determining gestational age with BPD and FL is reduced and the specific fetal conditions, such as improper positions or some fetal anomalies make it difficult to determine gestational age using the above diameters (8).

\section{Objectives}

Since no study in Iran and only one study in the world (9) has investigated the gestational age determination through measurement of anterior-posterior thigh diameters (APTD), this study aimed to determine gestational age by measuring APTD and investigate the relationship between this parameter and other routine ultrasound parameters in determining gestational age. 


\section{Methods}

In this cross-sectional correlation analysis, 105 pregnant mothers with a gestational age of 18 to 28 weeks presenting to Imam Reza Hospital in Kermanshah, Iran for performing an ultrasound were selected through convenience sampling if they were willing to participate in the study. The inclusion criteria were having regular menstrual cycles and knowing the exact date of the first day of the last menstrual period (LMP); not having diabetes, hypertension, or a history of medication use; singleton pregnancy, no fetal anomaly, and no history of intrauterine growth retardation. Gestational age was determined using the first day of the last menstrual period by the project assistant. The project executor who was blinded to subjects' LMP determined gestational age by measuring APTD at the widest part of the thigh from anterior to posterior skin along with routine ultrasound parameters (BPD and FL) using a Siemens G40 ultrasound device and Canucks 5 - 5.3 MHz probe. In estimating gestational age based on APTD, each millimeter of APTD size was considered as one week of gestation (Figure 1). Collected data were analyzed using SPSS-22 software. The KS test was used to determine the normality of measurements. Spearman correlation coefficient was then used for correlation analysis based on KS test. The significance level of the tests was considered 0.05 .

\section{Results}

A total of 105 pregnant women aged 15 - 43 years (26.59 $\pm 6.93)$ with a gestational age of $18-28$ weeks $(22.46 \pm 3.19)$ participated in this study (Table 1 ).

Table 1. Descriptive Characteristics of Pregnant Women's Gestational Age Based on Routine Ultrasound Parameters

\begin{tabular}{lcc}
\hline Variable & Size, millimeters & Mean \pm SD \\
\hline BPD & $40-71$ & $52.92 \pm 9.48$ \\
FL & $27-55$ & $39.8 \pm 2.67$ \\
APTD & $18-28$ & $22.3 \pm 28.1$ \\
\hline
\end{tabular}

Abbreviations: APTD, anterior-posterior thigh diameters; BPD, fetal biparietal diameter; FL, femoral length.

The findings of this study and Spearman's test showed a significant direct relationship between gestational age estimation based on routine ultrasound parameters (BPD, FL, APTD) and LMP (P < 0.05) (Table 2). Also, Spearman's correlation coefficient showed a significant direct relationship between gestational age determination by measuring APTD and gestational age estimation by BPD and FL (P < 0.05) (Table 3 and Figure 2). Hence, based on the findings of this study, in addition to BPD and FL, APTD can be used for determining gestational age in the second trimester.

\begin{tabular}{lcc}
\hline Table 2. Correlation Coefficient and Determination of the Relationship Between \\
Gestational Age Estimation Based on Routine Ultrasound Parameters and LMP \\
\hline Gestational Age Parameter & \multicolumn{2}{c}{ LMP } \\
\cline { 2 - 3 } & Correlation Coefficient & PValue \\
\hline BPD & 0.991 & $<0.001$ \\
FL & 0.991 & $<0.001$ \\
APTD & 0.992 & $<0.001$ \\
\hline
\end{tabular}

Abbreviations: APTD, anterior-posterior thigh diameters; BPD, fetal biparietal diameter; FL, femoral length; LMP, last menstrual period.

Table 3. Correlation Coefficient and Determination of the Relationship Between Gestational Age Estimation Based on BPD and FL Routine Ultrasound Parameters and APTD

\begin{tabular}{lcc}
\hline Variables & \multicolumn{2}{c}{ APTD } \\
\cline { 2 - 3 } & Correlation Coefficient & P Value \\
\hline BPD & 0.998 & $<0.001$ \\
FL & 0.997 & $<0.001$ \\
\hline
\end{tabular}

Abbreviations: APTD, anterior-posterior thigh diameters; BPD, fetal biparietal diameter; FL, femoral length.

\section{Discussion}

The present study investigated compliance of APTD with routine parameters of BPD and FL in estimating gestational age in 105 pregnant women aged 15 - 43 years (26.59 $\pm 6.93)$ with a gestational age of 18 - 28 weeks (22.46 \pm 3.19 ). Our results showed that determining gestational age by routine ultrasound parameters (BPD, FL) and APTD has a significant direct relationship with LMP. Also, gestational age estimation by APTD measurement had a significant direct relationship with gestational age estimation by FL measurement.

Selecting the appropriate ultrasound parameter is necessary for accurate estimation of gestational age for prenatal care. Ultrasound, on the other hand, runs the risk of observer error, so embryonic indices, different measurement methods, and local problems may reduce the accuracy of gestational age estimation (10-12). This, as a result, has encouraged researchers to assess current ultrasound parameters and offer new parameters (13). New and reliable methods for fetal biometry can be very useful in reducing overall fetal biometry errors and increasing reliability of determining gestational age (14). Selecting the most accurate biometric parameter depends on the time and purpose of measurement. For instance, BPD has the highest correlation with gestational age among other routine ultrasound parameters in the second trimester. Also, FL is the best parameter in the evaluation of skeletal/joint dysplasia (15). A study determining the gestational age of pregnant women in the second and third trimesters using 

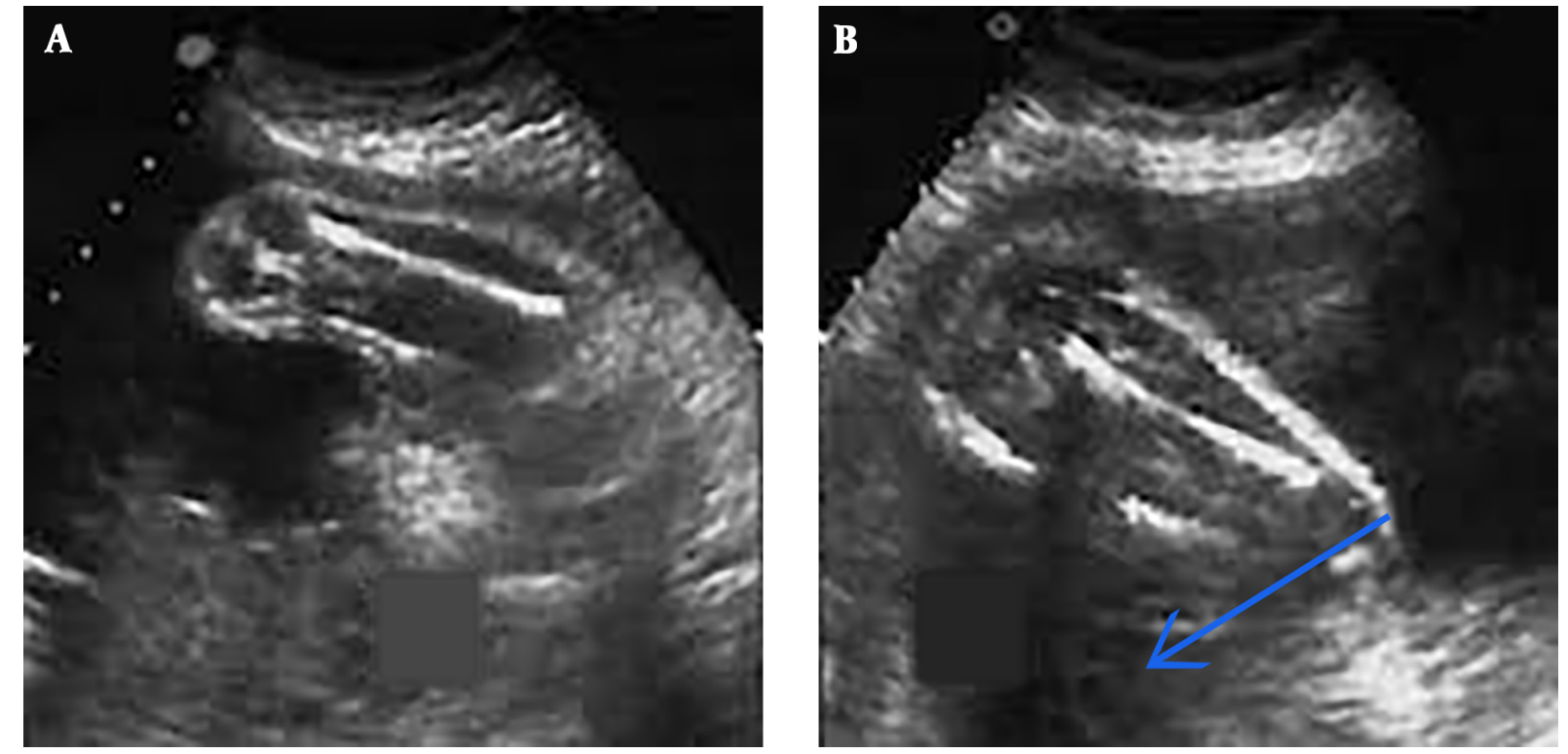

Figure 1. APTD measurement

A

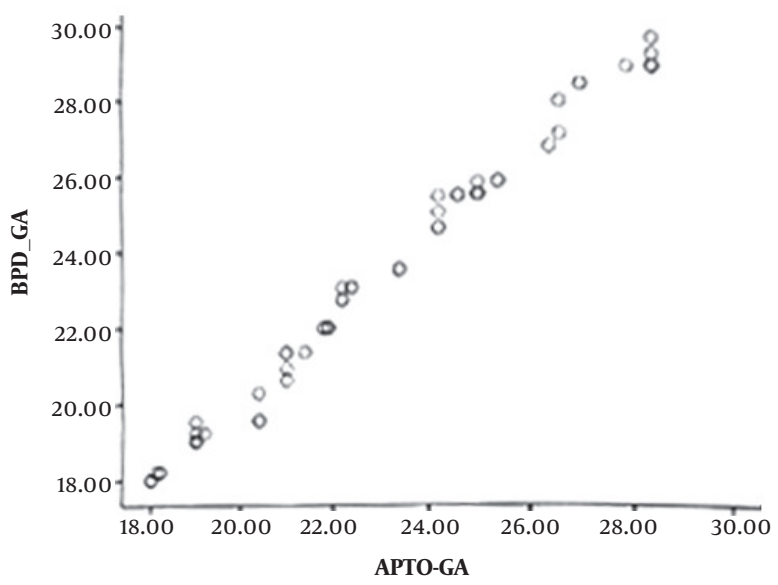

B

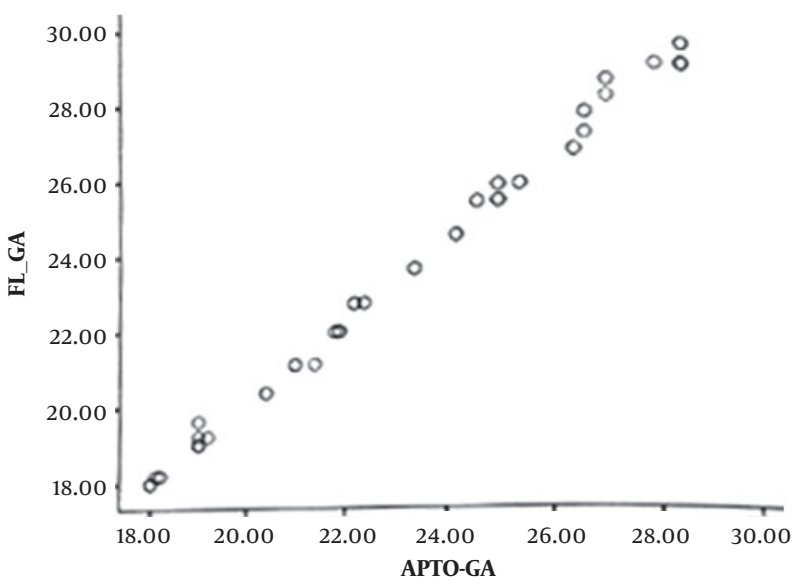

Figure 2. Distribution of gestational age by measuring APTD and estimating gestational age by A, FL; B, BPD

routine ultrasound parameters of BPD and FL and physical examination of fundal height (FH), found that the estimated gestational age using the routine ultrasound parameters was more accurate and faster than physical examination (16). The results of a review of past studies until 2013 showed that the estimation of gestational age in the second or third trimester using ultrasound should use a combination of parameters (BPD, HC, AC, and FL) rather than a single parameter (17).

In line with this study, Farshchian et al. examined 160 pregnant women with a gestational age of 15 - 40 weeks, and found that FL and BPD parameters had the highest correlation coefficient $(0.976,0.857$, respectively) with LMP in gestational age estimation (18). Also, another study by Farshchian et al. reported the correlation coefficient of FL with LMP in determining gestational age as 0.973 and correlation coefficient of BPD with LMP in determining gestational age as 0.976 (19). This was in line with the results of studies by Saheb Ghalam et al. (8).

APTD was examined only once in 2006 by Al-Kubaisi In 
line with the present study, they found that APTD measurement is a reliable method for assessing fetal age in normal pregnancy and may be useful when other parameters are unable to predict gestational age (20). Ultrasound in the first trimester has a high accuracy of about $3-5$ days. However, it is not possible to examine fetal dimensions at this period (21). Therefore, gestational age estimation is usually done in the second and third trimesters. However, gestational age estimation in the second and third trimesters is less accurate (22). In gestational age estimation based on APTD, each millimeter is considered one gestational week. APTD cannot be used after gestational age of 28 weeks because of an estimation error due to high fetal growth. APTD may also be used as an indicator of fetal biometric disorders like IUGR, and to empower physicians to better manage pregnancy. The significant correlation between APTD and LMP indicates that APTD is a reliable method, especially in cases where other fetal parameters cannot accurately predict gestational age.

Finally, it can be concluded that APTD has a significant direct relationship with other routine parameters such as BPD and FL in estimating gestational age in normal pregnancies. Therefore, using APTD along with other routine ultrasound parameters can be a reliable method.

One of the limitations of gestational age determination with APTD measurement is that it is less accurate in the third trimester of pregnancy due to increased fetal size and position of fetal lower limbs (which are bent) as well as a decrease in amniotic fluid volume, which is why current studies are performed in the second trimester.

\subsection{Conclusions}

According to the results of this study, APTD appears to have a significant direct relationship with other routine parameters such as BPD and FL in estimating gestational age in normal pregnancies. Therefore, APTD is reliable and can be used along with other routine ultrasound parameters.

\subsection{Recommendations}

Colleagues are recommended to conduct a similar study with a larger sample size.

\section{Acknowledgments}

This paper was extracted from a registered thesis (93235) by Mohammadreza Asrari. Authors sincerely thank Imam Reza Clinical Research Development Unit in Kermanshah for their support.

\section{Footnotes}

Conflict of Interests: There is no conflict of interest.

Ethical Approval: This manuscript approved by Kermanshah University of Medical Sciences (IR.KUMS.REC.1393.17185).

Funding/Support: Kermanshah University of Medical Sciences.

\section{References}

1. Cuningham FG, Leveno K, Bloom S, Spong CY, Dashe J. Williams obstetrics. 24nd ed. New York: McGraw-Hill; 2014. p. 1111-36.

2. McGahan J, Goldberg B. Diagnostic ultrasound. 2nd ed. New York: Informa Healthcare; 2008. p. 1069-94. doi: 10.3109/9781420004632.

3. Callen PW, Albanese C, Alexander R, Angtuaco T, Atri M, Babcook C. Ultrasonography in obstetrics and gynecology. 5th ed. Philadelphia: Saunders; 2008. p. 146-68.

4. Hadlock FP, Harrist RB, Deter RL, Park SK. Fetal femur length as a predictor of menstrual age: Sonographically measured. AJR Am J Roentgenol. 1982;138(5):875-8. doi: 10.2214/ajr.138.5.875. [PubMed: 6979176]

5. Hadlock FP, Deter RL, Harrist RB, Park SK. Fetal biparietal diameter: A critical re-evaluation of the relation to menstrual age by means of real-time ultrasound.JUltrasound Med.1982;1(3):97-104. doi: 10.7863/jum.1982.1.3.97. [PubMed: 6152941].

6. David S. Textbook of radiology and imaging. 7th ed. New York: Chercill Livingston; 2002. p. 7-1212.

7. Karki DB, Sharmqa UK, Rauniyar RK. Study of accuracy of commonly used fetal parameters for estimation of gestational age. JNMA J Nepal Med Assoc. 2006;45(162):233-7. [PubMed: 17189967].

8. Saheb Ghalam H, Panahi G, Dadgar S, Afzali N, Shaban M. [The comparison of the diagnostic value of fetal foot length measurement with the length of femur and fetal biparietal diameter in determining the gestational age]. Iran J Obstet Gynecol Infertil. 2008;11(4):9-13. Persian.

9. Kalish RB, Chervenak FA. Sonographic determination of gestational age. Ultrasound rev Obstet Gynecol. 2005;5(4):254-8. doi $10.3109 / 14722240500390166$.

10. Malhotra N, Kumar P. Measurement of fetal parameters. Ultrasound in obstetrics and gynecology. 3rd ed. Mumbai: Jaypee Brothers Medical Publishers Private Ltd; 1999. p. 92-8.

11. Malhotra N, Kumar P. Ultrasound and admission test in labour. Ultrasound in obstetrics and gynecology. 3rd ed. Mumbai: Jaypee Brothers Medical Publishers Private Ltd;1999. p. 198-200.

12. Malhotra N, Kumar P. Pitfalls in USG. Ultrasound in obstetrics and gynecology. 3rd ed. Mumbai: Jaypee Brothers Medical Publishers Private Ltd;1999. p. 386-8.

13. Vinals F, Munoz M, Naveas R, Shalper J, Giuliano A. The fetal cerebellar vermis: Anatomy and biometric assessment using volume contrast imaging in the C-plane (VCI-C). Ultrasound Obstet Gynecol. 2005;26(6):622-7. doi:10.1002/uog.2606. [PubMed:16254881].

14. Zelop CM, Borgida AF, Egan JF. Variation of fetal humeral length in second-trimester fetuses according to race and ethnicity. J Ultrasound Med.2003;22(7):691-3. doi:10.7863/jum.2003.22.7.691. [PubMed: 12862267].

15. Degani S. Fetal biometry: Clinical, pathological, and technical considerations. Obstet Gynecol Surv. 2001;56(3):159-67. [PubMed: 11254152].

16. Shah S, Teismann N, Zaia B, Vahidnia F, River G, Price D, et al. Accuracy of emergency physicians using ultrasound to determine gestational age in pregnant women. Am JEmerg Med. 2010;28(7):834-8. doi: 10.1016/j.ajem.2009.07.024. [PubMed: 20837264]. 
17. Butt K, Lim K, Diagnostic Imaging C. Determination of gestational age by ultrasound. J Obstet Gynaecol Can. 2014;36(2):171-81. doi: 10.1016/S1701-2163(15)30664-2. [PubMed: 24518917].

18. Farshchian N, IRANFAR S, Rezaei M. [Estimation of gestational age using ultrasound scan]. J Kermanshah Univ Med Sci. 2007;11(1):11-8. Persian.

19. Farshchian N, Fakheri T, Rezaei M, Ebrahimi HR. [Comparison of diagnostic value of fetal cerebellar hemisphere circumference measurement and routine ultrasonography parameters for determination of the gestational age]. Sci J Kurdistan Univ Med Sci. 2014;19(1). Persian.

20. Al-Kubaisi SR. Anterior-posterior thigh diameter measured by twodimensional sonography: Indicator of fetal age at 18 to 28 weeks gestation? Sultan Qaboos Univ Med J.2006;6(2):47-58. [PubMed: 21748135]
[PubMed Central: PMC3074917].

21. Harrington DJ, MacKenzie IZ, Thompson K, Fleminger M, Greenwood C. Does a first trimester dating scan using crown rump length measurement reduce the rate of induction of labour for prolonged pregnancy? An uncompleted randomised controlled trial of 463 women. BJOG. 2006;113(2):171-6. doi: 10.1111/j.1471-0528.2005.00833.x. [PubMed: 16411994].

22. Suh YH, Park KH, Hong JS, Noh JH. Prediction of prolonged pregnancy in nulliparous women by transvaginal ultrasonographic measurement of cervical length at 20-24 weeks and 37 weeks. J Korean Med Sci. 2007;22(1):89-93. doi: 10.3346/jkms.2007.22.1.89. [PubMed: 17297257]. [PubMed Central: PMC2693575]. 